\title{
Reply: Notes on Post-Critique
}

\author{
Aaron Koh (The Chinese University of Hong Kong)
}

\begin{abstract}
:
This essay argues that a useful grammar for doing post-critique has emerged from a trans-, inter- disciplinary dialogue on post-critique. I further make three propositions in the essay. First, I suggest that postcritique is an additive critical practice where resources for cultivating thinking, reasoning and evaluating draws on a constellation of approaches that combines this and that and reinvigorates critique in new directions. Second, postcritique repairs a 'negative' enterprise of critique that has become a culture of teaching in academia and schools. Third, more affirmative pedagogies of postcritique could be more welcoming and considered to be more constructive in authoritarian context.
\end{abstract}

Keywords:

additive critical practice; affirmative pedagogies and postcritique; post-critique grammar; reparative critique

It is such a treat to read a collection of brilliant essays that takes up 'post-critique' inspired by Hodgson et al.'s (2017), Manifesto for a Post-critical Pedagogy in the ninth issue of on_education (2020). Latour's (2004) influential piece: Has critique run out of steam? as well as the work of many other scholars (e.g., Anker \& Felski, 2017; Felski, 2015) are also the antecedent texts that sparked this chain of vibrant discussion.

In this commentary, I share my 'notes' after reading this ensemble of inspirational collection of essays. Indeed, my notes are literally characteristic of what notes are - brief points and ideas that emerged in the collection. It is not the intention of this commentary to present a systematic summary of all the articles collected in the issue. There is no space for this. Instead, drawing on Rita Felski's (2020) idea of "resonance" defined as a spirited lively attachment and connection to intellectual ideas, I share in my notes ideas that stimulated my thinking that also sparked some reflection.

What I think have usefully unfolded from this trans/inter- disciplinary conversation and dialogue about postcritique is a grammar for doing postcritique, although this grammar could be in want of another round of critique. By 'grammar', I mean a range of critical vocabularies introduced to engage in postcritique. To name but a few; for example, "caring critique" (after Laner (2020)) and what may be summed up as affirmative pedagogies of critique (after Anker (2020) and Thoilliez (2020)), inter alia. However, this grammar, is not bound by rules or limited by the strictures of methodologies and frameworks. Instead, I believe, on-going theoretical and methodological innovation will further develop an expanded grammar for doing postcritique.

Before I proceed to share my notes on what I take away from the volume of essays, some clarification of what 'post- critique' means is in order because the prefix 'post-' seems to have caused confusion/misunderstanding whether the term is spelt as a hyphenated word or without. At the level of semantics, if we take 'post-' literally to mean a break, a point of departure from something, then, post-critique suggests that critique is over. In some quarters, postcritique is misconstrued as anti-theory and anti-critique (Felski, 2020). It does not help that education has instrumentalized critique into an enterprise about "(creative) problem solving" and "critical thinking". Indeed, these are the buzzwords now in educational discourse where critical thinking is packaged as 21 st competency skills touted to have purchase in industry 4.0. The essays in the special issue correct all these misconceptions and present afresh a multidisciplinary perspective and approaches to show that critique is not over, but our post-truth, post fact geopolitical moment requires new angles of critique.

Thus, scholars in the special issue collectively challenge and transcend conceptually and methodologically the primacy and normativity of critique where teaching critique is guided by "the epistemic yield of qualities like difficulty, complexity, indeterminacy, ambivalence, paradox, ambiguity and contradiction" (Anker, 2020, p. 1). In other words, this is the standard flair of how teachers and students engage in critique in the classroom. Indeed, in the classroom our students are considered to be trained well in critique when they demonstrate that they can read against the grain, excavate the hidden ideologies and contradictions in a text. Perhaps, it is this formulaic approach to teaching critique that has turned the intellectual- pedagogical labour of critique to a repetitive exercise or what Latour (2004, p. 232) alluded to as the "debunking impetus" of critique. But, Anker (2020) as well as others in the collection of essays argue there is more to critique. 
Wortmann's (2020) essay clarifies that the 'post' in postcritique signifies progress. Similar to how the post in social theory is defined (e.g., post-structuralism, postmodernism, post-positivism), he argues that post-critique heralds the arrival of an appropriate moment (of time) and a departure from the debunking style characteristic of critique which he says suffers from "an overly negative way of speaking" (p. 3). Wortmann proposed that post-critique involves more emphasis on the positivity and less attention on the negatives.

While I concede with Wortmann that critique has earned itself a bad name 'swinging' to the negative for way too long, I think it is problematic to suggest that postcritique involves 'a little more of this' and/or 'a little less of that' as if critical practice can be calibrated on a scale of more or less, positive or negative. A more helpful conceptualization, I suggest, is to regard postcritique as an additive critical practice where resources for cultivating thinking, reasoning, evaluating draws on a constellation of approaches that combines this and that and takes critique in new directions. Here I am reminded of Rita Felski's (2020) astute insight that in seeking alternatives to critique, "we need to clarify how alternatives to critique can enrich or enhance understanding: how they affect or alter our view of what counts as knowledge" (p. 1).

What I think has emerged in the papers is a unifying effort to repair the 'negative' enterprise of critique that has become a culture of critique in academia and schools, which I think has done some damage to the reception of critique. I will return to this point later; suffice to say in cursory that being critical and the work of critique can invite hostility and sanctions. Several papers in the collection propose a reorientation of critique to focus on the affirmatives (as per Vlieghe \& Zamojski's (2020) article) while others like Laner (2020) argue that the core concerns of postcritique are "preservation, positive affection, hope and experience" (Laner, 2020, p. 1). In similar vein, Thoilliez extends "a postcritical invitation" and asks us to abandon cynicism and suspicions "to become an edifying educator" (Thoilliez, 2020, p.1). Anker (2020), too, joins in and argues that the goals of a postcritical education "promotes values such as trust, integrity, clarity, and noncontradiction" (p. 1). Clearly, these are critical departures of the debunking style of critique that also turn critique into a positive and more empowering endeavour. However, we need to be cautious not to throw the baby out with the bathwater. My point is moving from critique to postcritique should be treated as an additive enterprise; not a case of this or that, but this and that.

With a more positive emphasis in postcritique, perhaps, we could see a new engagement and less threatening reception of critique, particularly in authoritarian context and with authoritarian populism on the rise. I return here to elaborate why I say an endemic 'negative' culture of critique has done some damage to the reception of critique. I wrote some time ago about the politics of risks involved in critical scholarship in authoritarian regimes such as Singapore (Koh,
2008). In that article, I argue that "the risks and stakes are higher in more authoritarian/controlling regimes" because "the range of risks inherent in making any critical political intervention is often not made explicitly known" and "the discursive limits of what can or cannot be critiqued are wrapped in terms defined and set exclusively by the ruling regime" (p. 304). Often, critique in such context can invite sanctions in many forms. More pertinent to the context I currently work now, in Hong Kong, since the introduction of the National Security Law last year, there is underlying fear that academic work that is critical of the establishment or perceived to have crossed the thin red line of "national security" could invite repercussions. However, it remains to be seen if such fears are founded or are just rumours and speculations. Perhaps, with a new emphasis in postcritique that is generally more affirmative, critique could be more welcoming and considered to be more constructive by those in positions of power. How to do postcritique in authoritarian contexts, nevertheless, remains to be explored.

As I wrap up my notes, I think it is befitting that I attempt to answer one question that the editorial asked in the Editorial (2020) - a question related to education - and their question is, "What does the current lively debate on post-critical thinking say about the state of critique in the educational field?' As I work in the field of educational studies, I feel that I am well positioned to answer this question.

It was three years ago that I came across Rita Felski's and Elizabeth Anker's (2017) edited volume, Critique and Postcritique. I was drawn to that work immediately after reading the introduction. It provoked and informed my work on Critical Literacy Education. I felt that critical literacy can be advanced and refurbished with the thinking around postcritique. Having taught critical literacy in Australia, Singapore and Hong Kong, and reading what other scholars have written about the topic, I felt that the teaching of critical literacy was becoming somewhat repetitive where ideological digging, questioning asymmtrical power relations and a social justice orientation to critical reading seem like a ritual of 'drill-and-practice'. While it is important not to elide the epistemological traditions between literary analysis to which postcritique belongs and critical literacy which emerged out of Freirean critical pedagogy, I argue that we can draw inspiration from postcritique to reinvigorate literacy and English education (Koh, 2019). Of course, this is but one example in educational studies that has taken up postcritique.

New theoretical ideas take time to circulate and flourish. The same is with postcritique. Hodgson et al.'s (2017) Manifesto for a Post-Critical Pedagogy is beginning to gain traction. Now that a team of scholars have responded to the manifesto and published a collection of papers in an openaccessed online journal, we are very likely to see more scholars reading about postcritique and explore new ways of ushering a postcritique style of critique and debate in the classroom and out in the public domain. More is to come. 


\section{References}

Anker, E. S. (2020). Beyond ambiguity and ambivalence: Rethinking the tools of critique. On Education. Journal for Research and Debate, 3(9). https://doi.org/10.17899/on_ed.2020.9.7

Anker, E. S., \& Felski, R. (Eds.) (2017). Critique and postcritique. Duke University Press. https://doi.org/10.1215/9780822373049

Editorial Team (2020). The fatigue of critique? On Education. Journal for Research and Debate, 3(9). https://doi.org/10.17899/on_ed.2020.9.0

Felski, R. (2015). The limits of critique. University of Chicago Press.

Felski, R. (2020). Resonance and education. On Education. Journal for Research and Debate, 3(9). https://doi.org/10.17899/on_ed.2020.9.2

Hodgson, N., Vlieghe, J., \& Zamojski, P. (2017). Manifesto for a post-critical pedagogy. punctum books.

Koh, A. (2008). On Singaporean authoritarianism: Critical discourse analysis and contextual dissonance. Pedagogy, culture \& society, 16(3), 303-314. https://doi.org/10.1080/14681360802346671

Koh, A. (2019). Travelling with and teaching critical literacy in Singapore, Australia, and Hong Kong: A call for postcritique. Curriculum Inquiry, 49(2), 203-216. https://doi.org/10.1080/03626784.2019.1593788

Laner, I. (2020). Caring critique. Exploring pedagogical spheres between critical and post-critical approaches. On Education. Journal for Research and Debate, 3(9). https://doi.org/10.17899/on_ed.2020.9.8

Latour, B. (2004). Why has critique run out of steam? From matters of fact to matters of concern. Critical Inquiry, 30(2), 225-248. https://doi.org/10.1086/421123

Thoilliez, B. (2020). When a teacher's love for the world gets rejected. A post-critical invitation to become an edifying educator. On Education. Journal for Research and Debate, 3(9). https://doi.org/10.17899/on_ed.2020.9.11

Vlieghe, J., \& Zamojski, P. (2020). Earth-bound study as a post-critical response to the corona-crisis. On Education. Journal for Research and Debate, 3(9). https://doi.org/10.17899/on_ed.2020.9.5

Wortmann, K. (2020). Drawing distinctions: What is post-critical pedagogy? On Education. Journal for Research and Debate, 3(9). https://doi.org/10.17899/on_ed.2020.9.1

\section{Recommended Citation}

Koh, A. (2020). Notes on post-critique. On Education. Journal for Research and Debate, 3(9). https://doi.org/10.17899/on_ed.2020.9.13

\section{About the Author}

Aaron Koh is an interdisciplinary scholar. He is an Associate Professor at The Chinese University of Hong Kong, Faculty of Education. He is the co-editor of International Studies in Sociology of Education (Routledge, Francis \& Taylor) and book series editor of Cultural Studies and Transdisciplinarity in Education (Springer). His most recent publications include a co-authored book, Class Choreographies: Elite Schools and Globalization (London, Palgrave, 2017) and a co-edited book, Elite Schools: Multiple Geographies of Privilege (London, Routledge, 2016). 